\title{
The lateral line microcosmos
}

\author{
Alain Ghysen ${ }^{1}$ and Christine Dambly-Chaudière \\ Laboratory of Neurogenetics Institut National de la Santé et de la Recherche Médicale (INSERM) U881, \\ 34095 Montpellier, France
}

\begin{abstract}
The lateral-line system is a simple sensory system comprising a number of discrete sense organs, the neuromasts, distributed over the body of fish and amphibians in species-specific patterns. Its development involves fundamental biological processes such as long-range cell migration, planar cell polarity, regeneration, and postembryonic remodeling. These aspects have been extensively studied in amphibians by experimental embryologists, but it is only recently that the genetic bases of this development have been explored in zebrafish. This review discusses progress made over the past few years in this field.
\end{abstract}

Souvienne vous de celui à qui, comme on demandait à quoi faire il se peinait si fort en un art qui ne pouvait venir à la connaissance de guère de gens: J'en ai assez de peu, répondit-il, j'en ai assez d'un, j'en ai assez de pas un.

Michel de Montaigne, Essais, Livre I, Chap. XXXVIII

(Remember the person who, when he was asked why he was working so hard on something that would come to the attention of scarcely anyone: I will be satisfied with a few, he answered, I will be satisfied with one, I will be satisfied with no one.)

The lateral-line system of fish and amphibians comprises a set of discrete sensory organs and the neurons that innervate them. Both electrosensory and mechanosensory organs are present in many fish species, but only mechanosensory organs (neuromasts) are present in zebrafish. At the core of each neuromast is a group of sensory hair cells that respond to the deflection of their cilia. Neuromasts therefore provide information about the local water flow. The system was discovered more than a century ago (for review, see Dijkgraaf 1989) and was long assigned an auditory function, mostly because its mechanosensory hair cells are very similar to those of the inner ear. The current view, however, is that the lateral-line system mediates a sense of "touch-at-a-distance" (Dijkgraaf 1963).

[Keywords: Lateral line; hair cells; zebrafish; cell migration; regeneration; planar cell polarity]

${ }^{1}$ Corresponding author.

E-MAIL alain.ghysen@univ-montp2.fr; FAX 33-4-67143928.

Article is online at http://www.genesdev.org/cgi/doi/10.1101/gad.1568407.
This sensory system is involved in a large repertoire of behaviors, e.g., swimming against current, prey detection and/or predator avoidance, social behaviors such as schooling, and sexual courtship (Coombs and Montgomery 1999). The idea of a "distant-touch" sensory system has been explored in the context of improving underwater safety for human devices, and an artificial lateral line has been developed (Yang et al. 2006) that shows an amazing capability to analyze movements of nearby bodies and wake signatures (water eddies).

The lateral-line system comprises two major branches, an anterior part that extends on the head, and a posterior part that extends on the trunk and tail. The development of the posterior lateral-line system (PLL) has been studied in amphibians and was shown to involve the formation of a migrating primordium that deposits small groups of cells, each one a prospective neuromast, in its wake (Harrison 1904). A migrating primordium was later demonstrated to initiate the development of the PLL in zebrafish, as well (Metcalfe et al. 1985). Most of the recent work refers to the posterior lateral-line system; the development of the anterior lateral-line system, which extends on the head, has not been much analyzed so far. However, it certainly differs from the posterior system in many respects, not the least of which is its independence on the molecules that drive migration of the posterior system.

The potential of the PLL to shed light on important developmental mechanisms, because of its structural simplicity and experimental accessibility, has recently been recognized (for review, see Ghysen and DamblyChaudière 2004). In this review we will focus on several aspects of lateral line development that have made considerable progress over the past 2 to $3 \mathrm{yr}$. Our aim is to give an overview of the perspectives that have been opened by this recent work, in relation to a small number of fundamental biological questions such as longrange cell migration, planar cell polarity, regeneration, and size control. This has led us to mention and discuss ideas and models that still lack rigorous demonstration, because we believe that the present strength of the system is precisely to provoke ideas and invite thought.

\section{Background: development of the zebrafish PLL}

The PLL originates as a placode that forms just posterior to the otic vesicle. The mechanisms involved in the induction of lateral-line placodes have been extensively 
reviewed recently and will not be dealt with here (Baker and Bronner-Fraser 2001; Schlosser 2002a,b; see also Schlosser 2006). In zebrafish, the PLL placode delaminates at $18-20 \mathrm{~h}$ post-fertilization (hpf) by a still poorly understood process (Kimmel et al. 1995). It rapidly divides into a small anterior compartment of $\sim 20$ cells that differentiate as sensory neurons and form the PLL ganglion, and a large compartment of $\sim 100$ cells, the PLL primordium. At $20 \mathrm{hpf}$, the primordium begins to migrate caudally at a speed of $\sim 150 \mu \mathrm{m} / \mathrm{h}$ (Fig. 1A), and reaches the tip of the tail at $\sim 40 \mathrm{hpf}$. As the primordium migrates, it is accompanied by axons extending from the ganglion (Metcalfe 1985; Gilmour et al. 2004). Glial cells in turn migrate along the axons (Gilmour et al. 2002) to form the myelinated PLL nerve (Brösamle and Halpern 2002)

The migrating primordium deposits five groups of $\sim 20$ cells, the proneuromasts, in its wake (Fig. 1B). Deposition results from a concerted slowing down of the cells at the trailing edge of the primordium /Gompel et al. 2001;
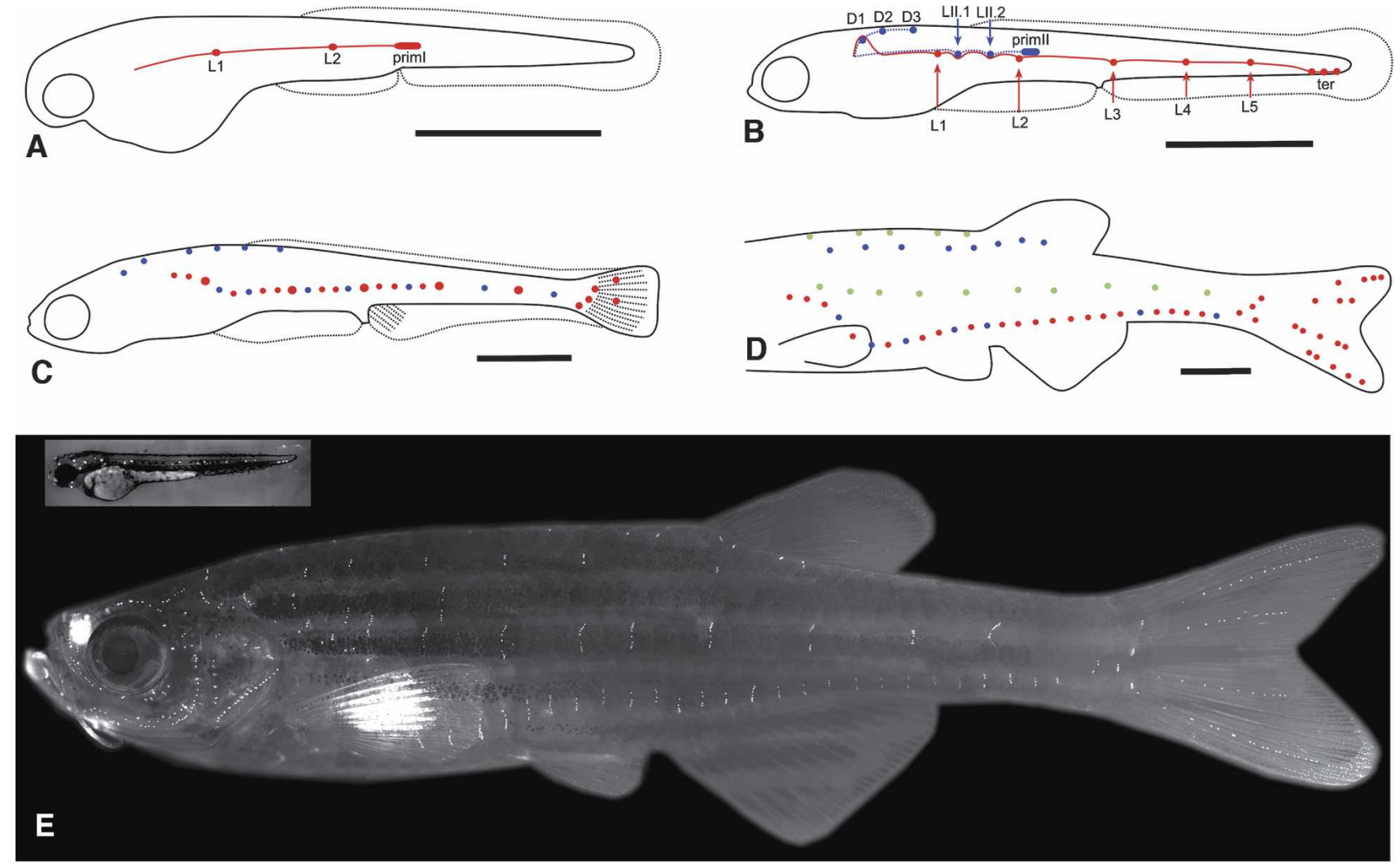

Figure 1. Development of the posterior lateral-line system (PLL). (A) At 32 hpf, the migrating primordium is about halfway in its journey to the tip of the tail. It has deposited two neuromasts, L1 and L2, as well as a thin stream on interneuromastic cells (red). (B) At $3 \mathrm{~d}$, primI has reached the tip of the tail where it fragments to form two to three terminal neuromasts (red). A second primordium forms $\sim 36 \mathrm{hpf}$ and splits to form primII, which follows the same path as primI along the horizontal myoseptum, and primD, which initiates the dorsal line (blue). (C) At $3 \mathrm{wk}$, intercalary neuromasts are formed by the interneuromastic cells deposited by primI (red). At this time, primD and primII have completed their journey (blue). The dorsal line never extends beyond the dorsal fin. The lateral neuromasts are shifting to more ventral positions. (D) At the larval-juvenile transition, the lateral and dorsal lines are complete and are shifted ventrally. Two new lines have formed at the original positions at the embryonic lines: one along the horizontal myoseptum and one along the dorsal midline (light green). (E) Young adult fish exposed to a fluorescent vital dye specific for hair cells. All individual neuromasts of the juvenile have given rise to dorso-ventrally aligned clusters of neuromasts (stitches). Stitches continue to expand during the entire life of the fish. (Inset) 48-hpf embryo at the same scale as the adult. Scale bars, $1 \mathrm{~mm}$. 
derived from primI and primII migrates ventrally (Fig. $1 C$; Ledent 2002). Thus, at $2-3$ wk, the larval PLL comprises two lines of neuromasts, a ventral one that includes neuromasts deposited by primI and primII, and a dorsal one (Fig. 1C). Over the following several weeks, the neuromasts of the dorsal line also migrate ventrally, and two new lines of neuromasts form at the same lateral and dorsal positions where the embryonic lines first appeared (Fig. 1D, green dots). In a final step of amplification, each neuromast gives rise to dorso-ventrally elongated clusters of neuromasts called "stitches" (Fig. 1E).

\section{Control of cell migration and deposition}

The first step in PLL development is the migration of the primordium along the horizontal myoseptum that separates dorsal from ventral somitic muscles. What determines the path and directionality of migration? The migrating cells express the gene $c x c r 4 b$, which codes for a homolog of the mammalian chemokine receptor CXCR4. The expression of $c x c r 4 b$ is not homogeneous, though: It is down-regulated in the trailing cells of the primordium, those that are about to slow down and become a deposited proneuromast, suggesting a possible involvement of CXCR4 in the control of migration (Fig. 2C; Gompel et al. 2001). The ligand of this receptor, $\mathrm{SDF} 1$, is present on a stripe of cells defining the path along which the primordium migrates. Inactivation of either the ligand or its receptor dramatically affects migration (David et al. 2002). Depending on the inactivating method (by mutation or with various morpholinos), the migration of the PPL primordium can be completely blocked or become randomly oriented (David et al. 2002; Li et al. 2004; Haas and Gilmour 2006). A similar result has been observed in a cxcr 4 mutant of the distantly related Oryzias latipes (medaka), arguing that the CXCR4/SDF1 mechanism is probably used by all teleosts (Yasuoka et al. 2004). cxcr4b is not expressed by the migrating primordia of the anterior lateral-line system, however, nor is SDF1 present along their migration trails, indicating that other guidance systems must control migration of the head lines.

The conclusion that the SDF1/CXCR4 interaction is central to the control of migration raises several questions, one of which is: What defines the midbody stripe of SDF1? This stripe corresponds to the region of the horizontal myoseptum, which separates dorsal from ventral body muscles. Expression of $s d f 1 a$ in this region ultimately depends on shh signaling from the notochord, since perturbing the shh signaling pathway, or altering the development of the notochord, abolishes the formation of the horizontal myoseptum (Odenthal et al. 1996). The nature and origin of the cells that express sdffa is not clear, however.

Another question is, does SDF1 act at a distance or as a bound molecule? This question is an important one, given that CXCR4 is present on many types of cancer cells, and SDF1 signaling has been implicated in their migration to secondary target sites (Müller et al. 2001).

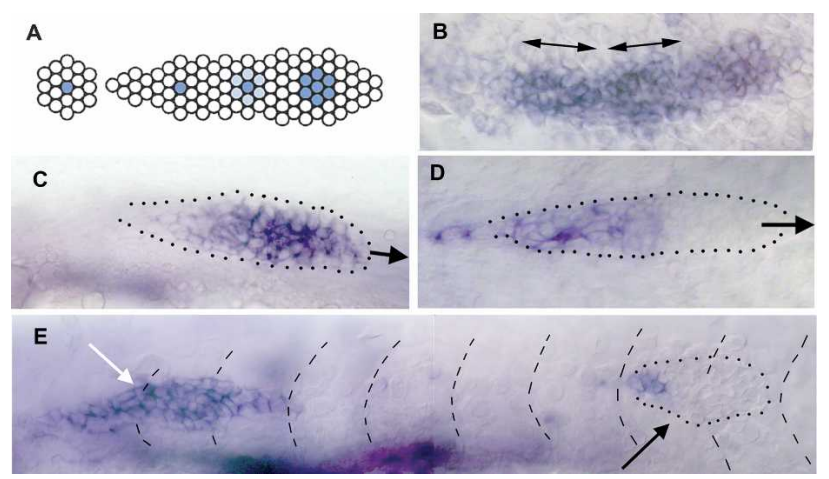

Figure 2. Patterning and polarization of primI. $(A)$ The expression of the proneural gene atoh1 (blue) defines two to three clusters of cells that prefigure the neuromasts. Expression of atoh is progressively restricted to a single hair cell precursor cell. (Reproduced with permission by Elsevier ( 2001 from Itoh and Chitnis 2001). (B) The expression of tacstd, a gene required for neuromast deposition, also reveals an intrinsic organization of the trailing region of the migrating primordium in two, or sometimes three, rosettes (double-headed arrows). (Reproduced with permission by Elsevier (c) 2001 from Gompel et al. 2001). (C) The gene $c x c r 4 b$ coding for the chemokine receptor CXCR4 is expressed in all cells of the primordium (dotted outline) and drives the migration to the right (arrow). (D) The gene cxcr7 coding for the chemokine receptor CXCR7 is exclusively expressed in the trailing cells of the primordium, and in the deposited cells (interneuromastic cells and neuromasts). A neuromast is being deposited by this primordium. After the primordium has completed deposition, the expression of cxcr7 is limited to a few cells at the trailing edge and expands again until the next deposition takes place. (E) Upon inactivation of $c x c r 4 b$ (or sdf1a), cxcr7 becomes expressed in all cells of the stalled primordium. In this exceptional case of a 35 -hpf $c x c r 4 b$ morphant embryo, the primordium has split in two halves. In the stalled half, all cells express cxcr 7 (white arrow), whereas in the migrating half, only the trailing cells express cxcr 7 (black arrow). The migrating half extends over somites $7-8$, while at this stage the primordium would have reached somites $18-20$ in a wild-type embryo. (Images in panels $C-E$, reproduced from Dambly-Chaudière et al. 2007.)

In the absence of the normal trail of SDF1 along the myoseptum, primordium cells tend to follow an alternative, more ventral trail of SDF1, suggesting that they are attracted by this second trail (David et al. 2002). Kuwada and colleagues relied on ectopic expression of the paralog gene $s d f 1 b$ to create patches of SDF1 in an otherwise mutant background (Li et al. 2004). They did observe several cases of the PLL primordium ending up at an ectopic position, close to the SDF1 patches, but the distance that the primordium had to travel in order to reach the SDF1-producing cells is difficult to evaluate. It is still not clear, therefore, whether SDF1 acts as a diffusible attractant, or whether the wandering primordium occasionally comes within filopodial reach of the SDF1 source.

What controls the periodic slowing down of trailing cells and subsequent deposition of proneuromasts? Two genes have been implicated in this process. tacstd codes for a putative calcium sensor. Its inactivation has no 
effect on migration but interferes with proneuromast deposition (Villablanca et al. 2006). As tacstd codes for a membrane protein and is highly expressed in the cells that are about to be deposited, it may be involved in the collective shift between migration and differentiation that takes place simultaneously in the 20 cells of the deposited cluster. The second gene, met, codes for a receptor tyrosine kinase and is mostly expressed in the leading cells of the primordium. Here again, gene inactivation has no effect on migration but interferes with proneuromast deposition (Haines et al. 2004). Interestingly, the ligand, Hgf (hepatocyte growth factor), is present at somitic boundaries. Local activation of Met might conceivably account for the observation that neuromasts are invariably located at somitic borders, and in its absence the primordium would become blind to appropriate landing spots.

One major feature of deposition is the simultaneous arrest of $\sim 20$ cells to form a proneuromast, implying some mechanism to partition the primordium. Prepatterning of the primordium in clusters that correspond to the future proneuromasts can be seen with a number of markers. The expression of the proneural gene atoh1 and of the neurogenic genes Delta and Notch identifies two to three clusters within the trailing half of the primordium, suggesting that only the leading third is fully unpatterned (Fig. 2A; Itoh and Chitnis 2001; Sarrazin et al. 2006). A rosette-like organization defining two to three clusters can also be detected after BrdU incorporation; these clusters correspond to the clusters identified by atoh1 expression (Laguerre et al. 2005). The presence of rosettes in the trailing half of the primordium is also revealed by the expression of tacstd (Fig. 2B; Villablanca et al. 2006).

It can be concluded that the migrating cells become progressively patterned in rosettes, each of which prefigures a proneuromast, and that this patterning affects gene expression as well as cell shape and behavior. The mechanism that achieves this patterning is still unknown. Given the importance of rosettes as a supracellular level of organization in other morphogenetic processes (Blankenship et al. 2006), understanding the mechanism that underlies this process will be of great importance.

\section{Directionality of migration}

Our understanding of migration directionality has been much advanced by the discovery that a very small number of $c x c r 4 b^{+}$cells in an otherwise $c x c r 4 b^{-}$primordium are sufficient to drive the entire primordium (Haas and Gilmour 2006). This could be due to "towing" of the $c x c r 4 b^{-}$cells, but closer examination reveals that these cells are polarized and actively migrate. Thus, it appears that cells are capable of migrating even in the absence of CXCR4, but they do not migrate because they recognize neither path nor direction. Since a few $c x c r 4 b^{+}$cells at the leading edge are sufficient to organize the entire primordium, these cells must confer to their neighbors some sort of self-propagating polarization.
There are two major mechanisms whereby the leading cells could organize the entire primordium: They may produce some chemical attractant that drives the followers to follow, or else their own movement may exert a force that polarizes the cytoskeleton of their followers. As the followers migrate in turn, they would transmit this force to their own followers all the way down to the trailing edge (for review, see Lecaudey and Gilmour 2006). At the moment, we do not know which of the two hypotheses apply, or whether both do, although a number of observations favor the second one (Haas and Gilmour 2006).

What is the basis for the directionality of migration? Probably not a gradient in SDF1 concentration along the antero-posterior $(\mathrm{A} / \mathrm{P})$ axis: No such gradient can be detected at the level of $s d f 1 a$ expression, and when a migrating primordium is confronted by a gap in the SDF1 trail, it occasionally doubles back upon itself and follows the SDF1 trail in the opposite direction, from tail to head (Haas and Gilmour 2006). An explanation for the intrinsic polarization of the primordium has recently been proposed, based on the expression pattern of the gene $c x c r 7$, which codes for another chemokine receptor, CXCR7. This receptor was long considered an orphan receptor but recently turned out to bind SDF1 with a very high affinity (Burns et al. 2006). The corresponding gene, cxcr 7 , is expressed exclusively in the trailing cells of the primordium-those that are about to slow down and be deposited (Fig. 2D; Dambly-Chaudière et al. 2007; Valentin et al. 2007). Paradoxically, however, the inactivation of $c x c r 7$ prevents migration altogether, much as the inactivation of $c x c r 4 b$ does.

The explanation that we proposed is that CXCR7 sequesters SDF1 in the trailing cells of the primordium, making it unavailable for CXCR4. Since CXCR7 is not present in the leading cells, this would ensure a global anisotropy of the primordium, with CXCR4-active cells at the leading edge and CXCR4-inactive cells at the trailing edge. Why is it, then, that CXCR7 is expressed specifically in the trailing cells? Morpholino inactivation of either $c x c r 4 b$ or $s d f 1 a$ shows that when the SDF1/ CXCR4 pathway is inactive, cXcr 7 is now expressed equally in all cells of the stalled primordium. In a few exceptional but illustrative cases, the placode has split in two parts, one of which remains stalled while the other migrates, albeit very slowly, toward the tip of the tail. In such cases, the stalled part shows a homogeneous expression of $\mathrm{Cxcr} 7$, while in the migrating part the expression is confined to the trailing region (Fig. 2E). Altogether, these results lead to the conclusion that the activation of CXCR4 by SDF1, in the leading cells of the migrating primordium, represses $\operatorname{cxcr} 7$, while the presence of CXCR7 in the trailing cells inhibits the activation of CXCR4 by sequestering its ligand (DamblyChaudière et al. 2007).

According to this model, the primordium would be driven by a gradient of SDF1/CXCR4 signaling, but this gradient would be generated by the primordium itself rather than depend on an external gradient in SDF1 concentration. The intrinsic polarization of the primordium 
might be set up at a very early phase of migration. As the primordium forms and elongates, only its posteriormost cells (prospective leading cells) come in contact with the $s d f 1 a$-expressing stripe of cells along the horizontal myoseptum. It is shortly after this time that $\operatorname{cxcr} 7$ first becomes expressed in the anteriormost cells (the presumptive trailing cells), thereby stamping an indelible arrow on the migrating primordium (Dambly-Chaudière et al. 2007).

A similar effect of $\mathrm{cxcr} 7$ inactivation on primordium migration has since been reported by Valentin et al. (2007). There are, however, intriguing differences between the results of Dambly-Chaudière et al. (2007) and those of Valentin et al. (2007). The clearest difference is that the latter investigators observe that the expression of $\operatorname{cxcr} 7$ is still confined to the trailing region of the primordium in mutant conditions for either $c x c r 4 b$ or $s d f 1 a$. In their experiments, however, the primordium has the very elongated shape typical of migrating primordia, while stalled primordia tend to assume a rounder or more irregular shape. One possible explanation for the discrepancy is, therefore, that in the mutant condition used by Valentin et al. the primordium is very much slowed down but not stalled, as was already observed by Li et al. (2004). Dambly-Chaudière et al., on the other hand, used morpholino inactivation and concentrated on those fish where the primordium had not moved at all by 32-35 hpf. Another experimental difference is that the major tool of Valentin et al. (2007) is time-lapse analysis of primordia, while Dambly-Chaudière et al. (2007) relied mostly on the final pattern of neuromasts to assess migration defects.

Based on their results, Valentin et al. (2007) conclude that CXCR4 and CXCR7 act independently of each other to regulate migration, while Dambly-Chaudière et al. (2007) proposed that the two receptors act antagonistically. The two conclusions are not mutually exclusive and may in fact reinforce each other. In support of this duality, Dambly-Chaudière et al. have noted that the carboxy-terminal ends of the fish and human CXCR7 receptors are very highly conserved, although they differ almost completely from the CXCR4 carboxyl terminus. This observation is consistent with the idea from Valentin et al. that CXCR7 does have a signaling activity, although not through the classical G Protein Coupled Receptor pathway. If both conclusions are indeed valid, then small differences in experimental design and conditions may have emphasized one or the other aspect of the interaction. What exactly the nature of the CXCR7 signaling is, and what its independent function is in regulating primordium migration, remain to be elucidated.

\section{Control of hair cell polarization}

An essential feature of the hair cell is that it has a planar polarity, both morphologically and functionally (for review, see Hudspeth 1989). Morphologically, the kinocilium appears at the center of the apical surface but soon moves toward one side. A large set of stereocilia then form on the apical surface, with the longest stereocilia being closest to the kinocilium. Functionally, the hair cell depolarizes when the bundle of stereocilia moves in the direction of the kinocilium and hyperpolarizes when it moves in the opposite direction. Moving the cilia in an orthogonal direction has no effect, and moving in oblique directions will give intermediate responses. In general, neuromasts comprise roughly equal numbers of cells with opposite polarity, and zebrafish neuromasts conform to this rule. All neuromasts deposited by primI during embryogenesis are polarized along the $\mathrm{A} / \mathrm{P}$ axis.

The addition of new hair cells to a growing neuromast is a relatively slow process, and is difficult to study by time-lapse analysis. The process can be accelerated by eliminating all extant hair cells, e.g., by exposure to aminoglycoside antibiotics (Song et al. 1995; Santos et al. 2006). New hair cells are rapidly produced, allowing live imaging of the process (Lopez-Schier and Hudspeth 2006). Time-lapse videomicroscopy revealed that after hair cell ablation, individual support cells begin to express a hair cell marker (Parinov et al. 2004) and divide along the $\mathrm{A} / \mathrm{P}$ body axis a few hours later, thereby forming a pair of hair cells (Fig. 3A-F). The two
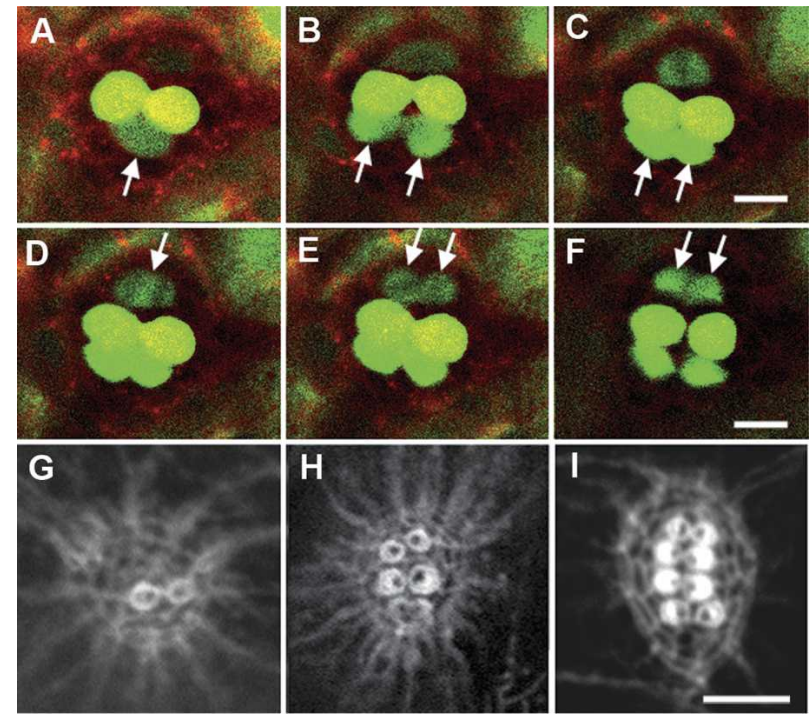

Figure 3. Mirror symmetry of regenerating hair cells. $(A-F)$ Single precursor cells divide to form two immature hair cells. $(G)$ As the hair cells differentiate, they form a central kinocilium surrounded by a set of actin-rich stereocilia (white in this figure, due to fluorescence of rhodamin-phalloidin). $(H)$ Within each pair of hair cells, the kinocilium moves toward the sib cell, resulting in a mirror-symmetrical polarization of the two cells. (I) As new precursor cells appear dorsal and ventral to the first pair, a dorso-ventral row of symmetrical pairs is generated. This simple pattern may help the afferent axons establish appropriate connections, as it is known that, of the two neurons that innervate each neuromast, one connects to all hair cells of one polarity, and the other connects to the hair cells of the opposite polarity (reproduced from Lopez-Schier and Hudspeth 2006, (C) 2006 National Academy of Sciences). 
cells of a pair are initially isotropic (Fig. 3G) but soon assume opposing polarities, each having its kinocilium displaced toward its sib (Fig. 3H). As new precursor cells are added dorsal or ventral to the existing pairs, two rows of hair cells are produced: an anterior row with its kinocilia pointing posteriorly, and a posterior row with its kinocilia shifted anteriorly (Fig. 3I). The simple arrangement of hair cells in two rows becomes blurred as the neuromast matures and the patch of hair cells becomes circular, but the presence of pairs of hair cells of opposing polarities is easily detected at all stages.

The generation of hair cells as mirror symmetrical pairs thus provides each neuromast with equal numbers of hair cells polarized in opposite directions. The symmetry within pairs suggests that the polarization of each cell could be determined by the position of its sibling, such that the two kinocilia would always move toward each other. A cue to the nature of this interaction comes from the effect of the trilobite mutation, which lacks the Vang12 protein. Vang12 is a component of the so-called Planar Cell Polarity system, which is involved in the establishment or maintenance of planar polarity in many systems, from eye ommatidia and hairs in Drosophila to the inner ear in mammals. Inactivation of Vangl2 has no effect on the orientation of the division of hair cell precursors, which remains properly aligned along the A/P axis. The movement of the kinocilium away from the apical center, however, is randomized, resulting in a failure of the hair cells to become properly polarized (LopezSchier and Hudspeth 2006).

If the patterning element in the polarization of hair cells is the axis of division of the precursor cell, what then determines this axis? One simple hypothesis is that the axis of division is imposed by the fish $\mathrm{A} / \mathrm{P}$ axis. Alternatively, since the migrating cells are polarized along the $\mathrm{A} / \mathrm{P}$ axis, this polarity could be retained upon deposition and used to orient the axis of precursor cell division. Support for this hypothesis comes from the observation that when primI follows an aberrant course, e.g., in the fused somites mutant, the orientation of neuromast polarity is aligned along the $\mathrm{A} / \mathrm{P}$ axis in $30 \%$ of the cases, instead of $100 \%$, while alignment along the axis of migration nears 70\% (Lopez-Schier et al. 2004). It appears, therefore, that the direction of last migration is a better predictor of neuromast polarity than the $\mathrm{A} / \mathrm{P}$ or $\mathrm{D} / \mathrm{V}$ axes of the animal, suggesting that neuromast polarity is intrinsic to the primordium and largely imposed by the direction of migration. A similar conclusion had been reached in amphibians (Smith et al. 1990).

\section{Post-embryonic growth: the origin of diversity}

At the end of its embryonic development, the zebrafish PLL normally comprises five pairs of lateral and two to three pairs of terminal neuromasts, and a pair of dorsal neuromasts close to the first somite (Fig. 4A). This pattern appears extremely conserved among teleosts (Pichon and Ghysen 2004). It is observed not only in the relatively basal ostariophysians (e.g., zebrafish and the blind tetra, Astyanax fasciatus) but also in groups that show many derived characters such as pleuronectids (flatfishes; Pichon and Ghysen 2004) and scombrids (tunafish; Kawamura et al. 2003). Fish continue to grow throughout their life, however, and their lateral-line system continues to develop. One might have imagined that the neuromasts simply get bigger, much as the eyes or the olfactory bulbs, but this is not so: rather, the number of neuromasts increases.

The PLL comprises seven to eight neuromasts in a 4-mm embryo, 28 in a $7-\mathrm{mm}$ larva, $~ 160$ in a $17-\mathrm{mm}$ young adult, and $\sim 580$ in a $33-\mathrm{mm}$ mature adult (sizes do not include the caudal fin) (A. Ghysen, unpubl.). Thus, neuromast numbers increase roughly as the square of body length, as appropriate for sensory organs spread on the body surface. The total number of hair cells on the body surface therefore increases dramatically from embryo to adult and keeps increasing during adulthood, although individual neuromasts tend to retain the same size at all ages.

The increase in neuromast numbers is accompanied by major changes in their pattern. In contrast to the highly conserved embryonic pattern, the adult patterns of lines and individual organs are extraordinarily diverse among species (e.g., Webb 1989). In zebrafish, diversity is generated post-embryonically through at least four very different mechanisms: intercalary growth, formation of a new primordium, budding, and (in the anterior line) formation of canals, as we will see in the following sections.

\section{Growth by intercalation: glial control of sensory development}

Activation of caged fluorescein in migrating cells has been used to identify all cells that are deposited by primI. This revealed the presence of a thin trail of cells that connects the neuromasts to each other (Gompel et al. 2001; Lopez-Schier et al. 2004); the same is true for primII (Sapède et al. 2002). These cells were wrongly assumed to be glial cells. Their nature was determined by Grant et al. (2005), who labeled the primordium cells by fluorescein uncaging and glial cells with the marker foxd3. They concluded that the interneuromast cells (INC) that are deposited by either primordium are interspersed with, but distinct from, glial cells. The latter originate from the neural crest, accumulate near the ganglion, and migrate along the growing peripheral axons to assume their final position along the PLL nerve.

INC can be visualized by the expression of claudin $b$, a gene expressed in migrating primordia and in neuromasts (Kollmar et al. 2001), by the enhancer-trap line ET20 (Parinov et al. 2004), or by histochemical detection of alkaline phosphatase activity (Villablanca et al. 2006). The trail of INC migrates ventrally, much as differentiated neuromasts do. As these cells move and become separated from the lateral-line nerve, local cell proliferation results in local thickenings of the trail (Grant et al. 2005; Lopez-Schier and Hudspeth 2005). The resulting local clusters will eventually become intercalary neuromasts. What is it that controls the transition from INC 

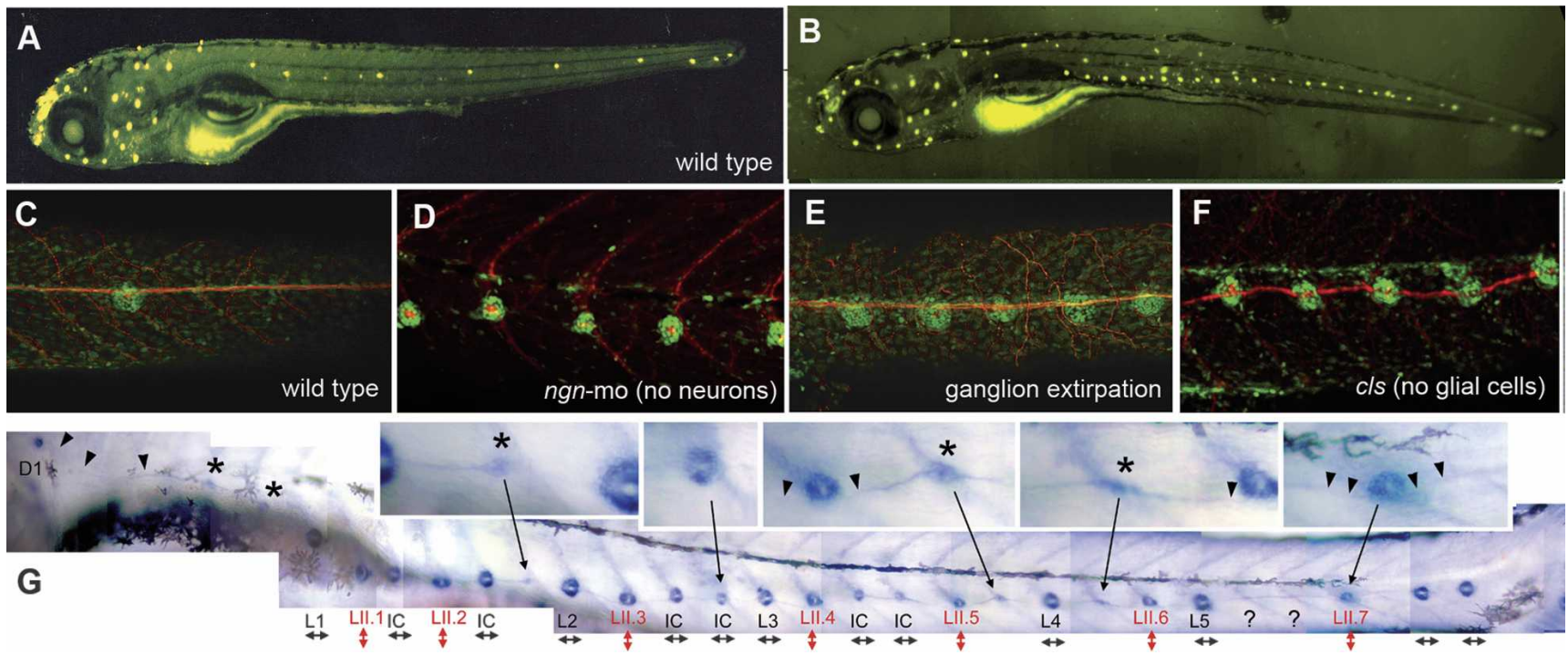

Figure 4. Formation of intercalary neuromasts. (A) Normal embryo at 4 dpf. Besides the neuromasts L1-L5 deposited by primI, two neuromasts deposited by primII can also be detected (tiny dots between L1 and L2). (B) An embryo at the same age where the ganglion has been laser-ablated just after primI has begun to migrate. A large number of intercalary neuromasts have precociously formed. $(C-F)$ Stretches of four to five somites in a wild-type embryo, an embryo where neurogenin has been inactivated, an embryo where the ganglion has been extirpated, and an embryo mutant for the colourless gene. (Green) Neuromast cell nuclei, (red) nerve fibers. Afferent neurons are absent in $D$, due to ngn inactivation; afferent fibers are present after ganglion extirpation, however, due to neural regeneration $(E)$. $(G)$ Seven-millimeter larva illustrating the formation of intercalary neuromasts (IC) by the thin trail of interneuromast cells, as visualized by alkaline phosphatase labeling (Villablanca et al. 2006). At this stage, the primary neuromasts deposited by primI can still be recognized based on size and position (L1, L2...). Several neuromasts have also been deposited by primII (LII.1, LII.2 ..., red); they are easily distinguished from primI neuromasts because they push the trail of INC in front of them (inserts). (Double arrows) Axis of hair cell polarization: All neuromasts derived from primI, including the intercalary neuromasts (IC), have their hair cells polarized along the A/P axis; all neuromasts deposited by primII are polarized along the dorso-ventral axis. (Asterisks) Positions where new focal clusters prefigure the formation of new intercalary neuromasts, (question marks) positions where the trail of interneuromast cells is still dormant. (Panels C-F reproduced with permission by Elsevier (C) 2005 from Grant et al. 2005; panels B,G, A. Ghysen and C. Dambly-Chaudière, unpubl.)

to intercalary neuromast? This question was solved by Grant et al. (2005) through a series of experiments ingeniously combining surgery and genetics. They showed that removal of the PLL ganglion through either genetic ablation (Fig. 4D) or physical extirpation (Fig. 4E) has no effect on the migration of the primordium or on the deposition of the early neuromasts, but results in the formation of a vast excess of neuromasts at $4 \mathrm{dpf}$ (Fig. 4B). The supernumerary neuromasts turn out to be precociously formed, INC-derived, intercalary neuromasts (Grant et al. 2005; Lopez-Schier and Hudspeth 2005). The obvious interpretation of these data would be that the sensory neurons exert an inhibitory influence on the formation of new sense organs - a fairly paradoxical conclusion.

A clue to the solution of this paradox comes from mutational analysis. Three mutants that present supernumerary neuromasts were examined. One of them has a generic defect in the neural crest and is deprived of most glial cells (Fig. 4F; Lopez-Schier and Hudspeth 2005), while the other two turn out to be deficient in glial cells along the PLL nerve but not around the PLL ganglion (Grant et al. 2005). Thus, glial cells seem to be the major factor in keeping the formation of intercalary neuromasts under control. This point was demonstrated by transplanting wild-type glial cell progenitors in mutant hosts and observing a rescue of the neuromast phenotype. The effect of ganglion removal is therefore indirect (Grant et al. 2005). The absence of axons connecting to the migrating primordium results in an absence of glial cells and thereby leads to the same phenotype as glial removal: formation of supernumerary neuromasts.

Given that glial cells prevent the differentiation of INC into neuromasts, why is it that intercalary neuromasts eventually form on each somite border? One possibility is that the ventral migration of INC separates them from the PLL nerve and its glia, and thereby removes the inhibition. The formation of intercalary neuromasts extends over a long period of time, however, and after $10 \mathrm{wk}$, there are still positions where the local thickening that foreshadows the formation of an intercalary neuromast has just begun (Fig. 4G, asterisks) or is still absent (Fig. 4G, question marks). At this age, the entire INC trail has moved a substantial distance from the horizontal myoseptum, implying that the inhibitory effect of glial cells should be mediated by a secreted molecule acting at a long distance.

An alternative possibility is based on the fact that intercalary neuromasts are individually innervated, and indeed the number of neurons in the PLL ganglion in- 
creases steadily during post-embryonic development (V. Chaar, C. Dambly-Chaudière, and A. Ghysen, unpubl.). The early contact with glia could put the INC in a dormant state, and this dormancy could be reverted by the arrival of naive sensory axons. The induction of intercalary neuromasts by their own afferent neurons would ensure not only that the number of neuromasts matches that of neurons, but also that the somatotopy of the intercalaries matches the somatotopy of the early neuromasts (Gompel et al. 2000).

\section{Growth by reiteration: primII and planar polarity}

A first process of neuromast addition is already operating at the end of embryogenesis. At $48 \mathrm{hpf}$, a new primordium, primII, has begun to migrate along the horizontal myoseptum toward the tip of the tail. The neuromasts deposited by primII are closer together than those of primI, with a spacing of two somites on average (instead of five for primI neuromasts). primII is part of a larger primordium that splits after reaching somite 1 , with one half (primII) migrating along the horizontal myoseptum much as priml did, and the other half (primD) moving toward the dorsal midline (Sapède et al. 2002). Upon reaching the dorsal midline, primD migrates posteriorly and pioneers the dorsal line, which eventually comprises about six neuromasts (Fig. 1B,C; Ledent 2002).

Activation of caged fluorescein in the post-otic region after primI has moved away results in labeling of both primII and primD (D. Sapède, C. Dambly-Chaudière, and A. Ghysen, unpubl.). This indicates that the secondary primordium appears in the same region where the embryonic PLL placode formed during embryogenesis. Given the complex interactions that are responsible for the formation of the PLL placode, it seems unlikely that a new placode is induced at this late stage. A more plausible explanation is that some placodal cells are left in a dormant state and resume development after primI has moved away. The exact nature and location of these putative dormant cells is still obscure.

An interesting difference between primI and primII neuromasts is that they differ in their polarity. As mentioned previously, all hair cells of the early neuromasts are polarized along the $\mathrm{A} / \mathrm{P}$ axis $(\mathrm{A} / \mathrm{P}$ neuromasts). Later on, however, some neuromasts have their hair cells oriented along the dorso-ventral axis (D/V neuromasts). Given the temporal and spatial correspondence between these $\mathrm{D} / \mathrm{V}$ neuromasts and the neuromasts deposited by primII, Lopez-Schier et al. (2004) proceeded to remove either primordium and examine the polarization of the remaining neuromasts. The results show that laser ablation of primI removes all $\mathrm{A} / \mathrm{P}$ neuromasts but has no effect on the later appearance of $\mathrm{D} / \mathrm{V}$ neuromasts, while the reciprocal removal of primII either by laser ablation or by mutation has no effect on $\mathrm{A} / \mathrm{P}$ neuromasts but precludes the formation of $\mathrm{D} / \mathrm{V}$ neuromasts. The result was confirmed by labeling primI with caged fluorescein: Fluorescent neuromasts display an $\mathrm{A} / \mathrm{P}$ polarity while unlabeled neuromasts are $\mathrm{D} / \mathrm{V}$ polarized.

One possible mechanism for the orthogonal polariza- tion of primI and primII neuromasts is related to the direction of migration prior to neuromast differentiation. The clusters of cells deposited by primI (proneuromasts) migrate posteriorly, stop migrating and differentiate as neuromasts, and later on migrate ventrally (Ledent 2002; Sapède et al. 2002). The proneuromasts deposited by primII, on the other hand, begin to migrate ventrally before they terminally differentiate. As noted by Whitfield (2005), this hypothesis would predict that intercalary neuromasts produced by primI should display a D/V polarization, since their ventral migration precedes their differentiation. This is not the case, however: All primI neuromasts, be they early or late (intercalary), show an A/P polarization (Fig. 4G; A. Ghysen, unpubl.). The hair cells within the neuromasts also display A/P polarization both in the embryonic and in the intercalary neuromasts that depend on primI (T. Piotrowski, pers. comm.).

The reciprocal situation is provided by the dorsal line. After reaching the dorsal midline, primD migrates antero-posteriorly along the midline. Here again the neuromasts show $\mathrm{D} / \mathrm{V}$ polarization much like primII neuromasts. It appears, therefore, that all neuromasts derived from primI have an $\mathrm{A} / \mathrm{P}$ polarity while all neuromasts derived from primII/primD (remember that these two arise from a single primordium) have a D/V orientation. Thus, primordium identity seems to be an important determinant of neuromast polarity during normal development, and may determine whether the axis of neuromasts will be parallel (primI) or orthogonal (primD and primII) to the direction of migration of the primordium. Interestingly, a similar conclusion has been reached in amphibians, some of which also have a dorsal line whose polarity is orthogonal to that of the ancestral lateral line (for review, see Schlosser 2002a). It may be that primII originated from the dorsal line, and that this is a derived feature of teleosts, but since the early development of either primII or primD has never been studied in any other fish species, the question remains open.

\section{Growth by budding: stitch formation}

A subsequent event in the development of the PLL is the formation of stitches. Stitches are closely packed, linear arrays of neuromasts. They form by budding from one founding neuromast and may include up to 10-20 neuromasts (Fig. 5D). The fact that all neuromasts of one stitch are innervated by repeated branching of the same neurons (Ledent 2002) supports the idea that they are all progenies of the founding neuromast. The analysis of stitch formation remains to be done, but we will nevertheless mention some intriguing properties as possible seeds for future analyses.

Early on, all stitches are elongated dorso-ventrally (Fig. $5 \mathrm{~A})$, although in late adults the pattern becomes somewhat disorganized (Fig. 5C). As far as can be determined, all neuromasts in stitches derived from primI retain an $\mathrm{A} / \mathrm{P}$ polarization while all neuromasts in stitches derived from primII and primD have a dorso-ventral polarization. This indicates that the early polarization of each neuromast not only is maintained 

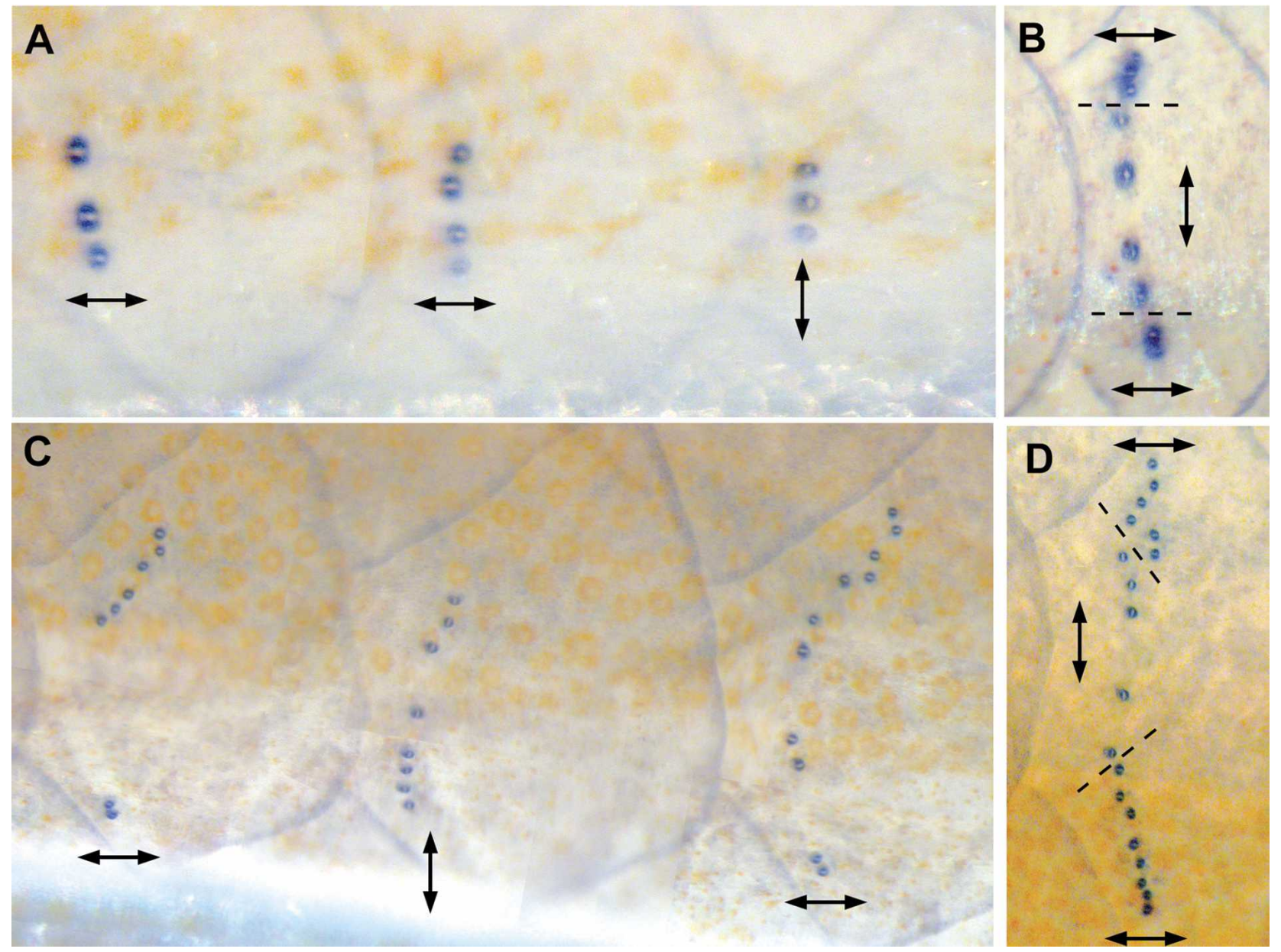

Figure 5. Formation of stitches. (A) Three consecutive stitches of the ventral line, which has formed by ventral migration of the embryonic PLL, in a 17-mm juvenile (alkaline phosphatase labeling) (A. Ghysen, unpubl.). The stitch at the right has all its neuromasts polarized dorso-ventrally and corresponds to a neuromast deposited by primII; the other two stitches show A/P polarization and correspond to two neuromasts deposited by primI. (B) A stitch of the late lateral line. This stitch appears to be composite: Its central neuromasts are polarized dorso-ventrally, while the more dorsal and ventral neuromasts are polarized along the $\mathrm{A} / \mathrm{P}$ axis. $(C, D)$ same as $A, B$ but in a $33-\mathrm{mm}$ mature fish.

throughout life, but also is somehow transmitted by the founding neuromast to all its progeny neuromasts. Alternatively, each newly budded neuromast may reestablish its polarity according to the animal axes. Either explanation offers interesting possibilities to examine how axial references are locally maintained from embryogenesis to adulthood. Late adults (old fish) still expand their stitches by budding additional neuromasts, but somehow they get confused, and neuromasts of the "wrong" polarity are occasionally produced.

Between the ventral and dorsal lines of the zebrafish lies a mysterious "late lateral line" (Fig. 1D, green dots). While all lateral derivatives of primI and primII have migrated ventrally early during larval life, a new line forms along the myoseptum when the fish is $\sim 1 \mathrm{~cm}$ long, that is, at the transition between larval and juvenile stages (Ledent 2002). The neuromasts of this line are on average two somites apart, and remain so during all stages. Nothing is known about the origin of this line. One would imagine that the late line is produced by a migrating primordium, much as the primary and secondary lines, although the idea of a primordium forming and migrating in the special context of a mature body is somewhat bizarre.

The real surprise, however, comes from the fact that stitches formed by this late line are mixed: Neuromasts on either side of the stitch are clearly polarized along the $\mathrm{A} / \mathrm{P}$ axis, while neuromasts at the middle are aligned along the dorso-ventral axis (Fig. 5B,D). This structure is unheard of in any stitch described to date in amphibians. Another major difference between zebrafish and amphibian stitches is that in amphibians the orientation of stitches is always correlated to the orientation of neuromasts (Schlosser 2002a), while in zebrafish all stitches are elongated dorso-ventrally irrespective of the polarization of the neuromasts. As mentioned above when discussing the origin of primII, these late developmental steps have not been studied in any other fish species, making it impossible to guess how these differences originated or how significant they are. 


\section{Growth in 3D: Canals and bones}

So far, we have considered the development of the lateral-line system as a two-dimensional problem. The system acquires its third dimension during postembryonic growth, when a subset of neuromasts becomes embedded in bony canals. On the trunk and tail, typically one canal is integrated into a row of specialized scales that are detectable with the naked eye, and form a "lateral line," thus giving the system its name. The pattern of canals is of important taxonomic value and has been extensively described in the past (Webb 1989; Northcutt 1997).

The location of neuromasts in canals may improve the detection of prey by shielding neuromasts from superficial turbulence and improving the signal/noise ratio. Another potentially significant difference between canal and superficial neuromasts is that the former respond preferentially to acceleration while the latter respond to the velocity of the water flow. Based on the central connectivity of lateral-line neurons, it has recently been proposed that the lateral line may assume a vestibular function in addition to its "distant-touch" function (Fame et al. 2006).

Head canals are systematically associated with dermal bones. For example, the supraorbital canal is associated with nasal and frontal bones, on the dorsal roof of the skull. This association may be due to subsequent fusion of dermal bones and canals that would form independently of each other ("two-component" theory, reviewed in Tarby and Webb 2003). According to this view, the association between canals and skull bones would be largely circumstantial. Alternatively, the association may be essential, if the formation of dermal bones and of canals both depend on a single initiation event ("onecomponent" view). Dermal bones and canal walls were shown to derive from a single ossification center in a species with many derived characters, leading to the hypotheses that the "one-component" development is a derived feature (Tarby and Webb 2003).

In zebrafish, a relatively basal species, no canal forms on the trunk, but they do form on the head. Recent work has shown that cranial canals and bones derive from common ossification centers, suggesting that the developmental association between canals and bones is an ancient one (Webb and Shirey 2003) and casting some doubt about the validity of the "two-component" theory. The question is undoubtedly important, as it relates to the origin of our skull, but it seems likely that the only way to settle it will be to explore the genetics underlying canal and bone formation.

Another interesting aspect of canals is that they increase in diameter after they initially form, as the fish grows. This process of remodeling bears on the interesting developmental problem of shaping three-dimensional objects such as bones. It has been noted for a long time that bones have precisely the shape that is best adapted to the forces and tensions that they are exposed to (Thompson 1917), but very little is presently understood about the genetic encoding of precise $3 \mathrm{D}$ shapes. In the case of lateral-line canals, the process of remodeling must involve not only bone expansion to allow for growth of the canal, but also bone resorption to allow for their widening. The two processes are probably mediated by the appropriate localization of osteoblasts and osteoclasts (Witten 1997), but nothing is known about the cues that control this localization. The genetic potential offered by the zebrafish combined to the simplicity of the canal structure may make this fundamental question amenable to genetic analysis.

\section{The measure of growth: neuromast entelechia}

In the mammalian inner ear, the full complement of hair cells is present at (or shortly after) birth, and hair cell loss cannot be compensated. Auditory damage, due, e.g., to exposure to loud sounds, is therefore irreversible. An alternative strategy was developed by fish, where neuromast hair cells are constantly renewed (Williams and Holder 2000). The number of hair cells remains fairly constant over extended periods of time, however, implying that neuromasts are in a state of dynamic equilibrium. How is this equilibrium achieved, and what is the mechanism that regulates hair cell renewal?

As mentioned in a previous section, the formation of new hair cells in neuromasts can be triggered by the removal of existing hair cells. Transient exposure to a low concentration of copper sulfate kills all functional hair cells but no other cell type (Hernandez et al. 2007). New hair cells are rapidly regenerated, suggesting that there is a pool of latent hair cell precursors that is prevented from forming new hair cells by a negative feedback from the existing hair cells. The number of hair cells that are regenerated is exactly the number that was present prior to the treatment, indicating that the number of precursor cells that are allowed to differentiate as hair cells at any given time is tightly regulated.

Surprisingly, the formation of new hair cells takes place without intervening BrdU incorporation. Since hair cells arise as paired progeny of single precursor cells (Lopez-Schier and Hudspeth 2006; see above), it follows that the precursor cells must be in the G2 stage of their cell cycle.

Exposure to higher concentrations of copper sulfate kills all cell types in the neuromast, preventing regeneration. At intermediate concentrations, the damage to support and to mantle cells is more limited, and regeneration of the neuromast can take place. The final number of hair cells is close to what it was before experimental treatment, as in the case of exposure to low concentrations. The dynamics of hair cell formation is slower, however, and is accompanied by increased BrdU incorporation (Hernandez et al. 2007). It appears, therefore, that the cell population must be replenished before a full complement of hair cells can be reestablished (see also Williams and Holder 2000). Where are the new cells coming from?

During normal development, the only neuromast cells that incorporate BrdU are peripheral cells (Williams and Holder 2000; Hernandez et al. 2007). An additional cue 
to the origin of new cells comes from amputation studies. It has been shown in amphibians that amputation of the tip of the tail is followed by regeneration, and that a regenerated lateral line is formed by a new primordium that arises from the neuromast closest to the cut (Stone 1937). When the caudal fin is amputated in adult zebrafish (this is the only fin where neuromasts are present), a similar process of regeneration takes place (Dufourcq et al. 2006). In this condition, massive BrdU incorporation is observed in the mantle cells of the neuromast closest to the cut, and newly formed cells migrate distally into the regenerating blastema, as in amphibians.

Based on the results of regeneration and on the analysis of several markers and reporter lines, a relatively simple view of self-renewal can be proposed (Fig. 6). The peripheral cells of the neuromasts (mantle cells) would react to a reduction in neuromast size (due, e.g., to hair cell death) by resuming cell division and producing new support cells. The support cells in turn can divide and produce pairs of hair cells. This hierarchy resembles the situation in the mammalian cortex, where radial glial cells can either self-renew or produce glial or neural precursor cells that may further divide to produce small clones of neurons (for review, see Ever and Gaiano 2005). Radial glial cells can also form adult neural stem cells (Merkle et al. 2004). Interestingly, neuromast mantle cells express a marker, ET20 (Parinov et al. 2004; Hern-
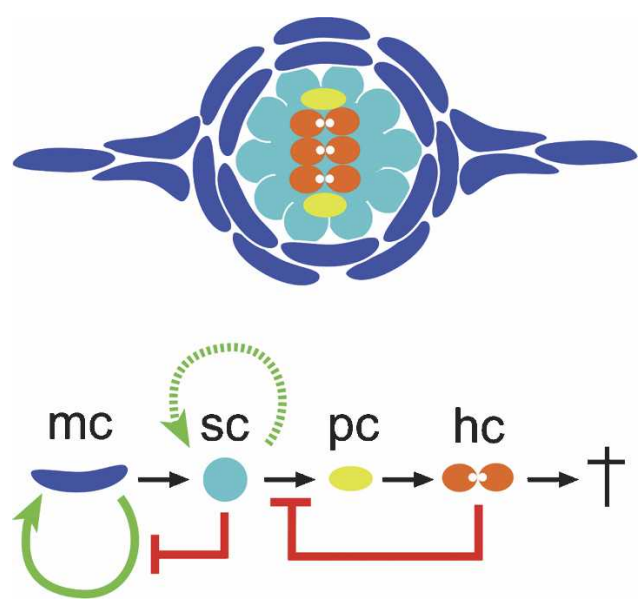

Figure 6. A possible scheme for hair cell renewal. The different fates are linearly organized, suggesting that each decision results from a simple binary choice, either "stay as you are" or "proceed to the next step." (Circular arrow) Self-renewing properties of the peripheral cells. (Dotted arrow) In experimental conditions, the support cell population may also be self-renewing (Hernandez et al. 2007), even though in normal neuromasts they are not (Williams and Holder 2000). (Red bars) Inhibitory feedback: New hair cell precursor cells form when hair cells die, and mantle cells enter S phase when the size of the neuromast decreases. Since BrdU incorporation is detected in peripheral cells and hair cell precursors divide in the central region, it seems likely that at least some of the support cells are in a $4 \mathrm{n}$ condition. (mc) mantle cell, (sc) support cell, (pc) hair cell precursor cell, (hc) hair cell, (cross) cell death. andez et al. 2007), that is also expressed by the INC. As described above, INC are capable of proliferating and forming intercalary neuromasts de novo, and mantle cells are capable of forming new migrating primordia after fin amputation.

A small proportion of peripheral, ET20 ${ }^{+}$cells express sox2, a gene that is expressed by all support cells (Hernandez et al. 2007). This finding supports the idea of a constant flux from mantle to support cell fate. The gene sox2 is a marker of neural progenitors in several other organisms, consistent with the idea that the support cells are precursors to sensory hair cells. Indeed, within the large population of sox2-expressing support cells, a small number show decreased sox2 expression concomitant with the onset of hair cell specific markers. Together, these data suggest a flow of fates from self-renewing mantle cell to support cell, support cell to hair cell, and hair cell to death, consistent with the observation that during normal development BrdU incorporation is observed at the periphery while new hair cells appear at the center of the neuromast (Williams and Holder 2000).

The fact that cell proliferation is enhanced in depleted neuromasts, and that full recovery can be achieved in a few days, indicates that somehow the cells of a neuromast can make a count of themselves or measure the size of the organ they belong to (Winklbauer and Hausen 1985) and adjust their proliferation parameters accordingly. In other words, cells know how big the neuromast is and how big it should be, and any disagreement between the two figures triggers DNA replication. How neuromast size is measured is not known. This property has been referred to as "Entelechia" (Garcia-Bellido and Garcia-Bellido 1998) in reference to the Aristotelian concept whereby the flying arrow already contains its path and target, and the fertilized cat's egg already contains the kitten within. While the arrow's entelechia has been fully explained by Newton's laws, the kitten entelechia has proved much more difficult to understand. Possibly the simplicity, small size, and autonomy of the neuromast will make this organ a good system to discover the mechanism by which it controls its own size and proportion of cell types.

\section{Conclusion}

In his excellent reviews about lateral-line placodes in amphibians, Schlosser (2002a,b) emphasized the surprising degree of autonomy of lateral-line development. Based on a rich collection of data accumulated by experimental embryologists during the past century, he concluded that everything about the adult lateral line seems to originate from the placode, except the pathways that migrating cells will follow. One might now add the glial cells as an "extraneous" factor, yet even so the development of the PLL remains remarkably autonomous. This extensive developmental autonomy makes this system nicely suited for a genetic analysis of essential processes such as the control of size, polarity, and patterning. Since these features are controlled from within the system, they may become more amenable to analysis than if the 
same questions were examined in more open systems where extensive interactions with the environment complicate the analysis.

\section{Acknowledgments}

We thank our colleagues Miguel Alllende, Hernan LopezSchier, Tatjana Piotrowski, Gerhard Schlosser, Jackie Webb, and Tanya Whitfield for critical comments on an earlier draft of this review; Darren Gilmour for communicating results prior to publication; and Mike Bate for help with the translation of Montaigne. Our work is supported by ARC (Association pour le Recherche sur le Cancer, France), ANR (Agence Nationale de la Recherche, France), and IUF (Institut Universitaire de France).

\section{References}

Baker, C.V. and Bronner-Fraser, M. 2001. Vertebrate cranial placodes I. Embryonic induction. Dev. Biol. 232: 1-61.

Blankenship, J.T., Backovic, S.T., Sanny, J.S., Weitz, O., and Zallen, J.A. 2006. Multicellular rosette formation links planar cell polarity to tissue morphogenesis. Dev. Cell 11: 459470.

Brösamle, C. and Halpern, M.E. 2002. Characterization of myelination in the developing zebrafish. Glia 39: 47-57.

Burns, J.M., Summers, B.C., Wang, Y., Melikian, A., Berahovich, R., Miao, Z., Penfold, M.E.T., Sunshine, M.J., Littman, D.R., Kuo, C.J., et al. 2006. A novel chemokine receptor for SDF-1 and I-TAC involved in cell survival, cell adhesion, and tumor development. J. Exp. Med. 203: 2201-2213.

Coombs, S. and Montgomery, J.C. 1999. The enigmatic lateral line system. In Comparative hearing: Fish and amphibians (eds. R.R. Fay and A.N. Popper), pp. 319-362. Springer Verlag, New York.

Dambly-Chaudière, C., Cubedo, N., and Ghysen, A. 2007. Control of cell migration in the development of the posterior lateral line: Antagonistic interactions between the chemokine receptors CXCR4 and CXCR7/RDC1. BMC Dev. Biol. 7: 23. doi: 10.1186/1471-213X-7-23.

David, N.B., Sapède, D., Saint-Etienne, L., Thisse, C., Thisse, B., Dambly-Chaudière, C., Rosa, F., and Ghysen, A. 2002. Molecular basis of cell migration in the fish lateral line: Role of the chemokine receptor CXCR4 and of its ligand, SDF1. Proc. Natl. Acad. Sci. 99: 16297-16302.

Dijkgraaf, S. 1963. The functioning and significance of the lateral-line organs. Biol. Rev. 38: 51-105.

Dijkgraaf, S. 1989. A short personal review of the history of lateral line research. In The mechanosensory lateral line (eds. S. Coombs et al.), pp. 3-14. Springer-Verlag, New York.

Dufourcq, P., Roussigne, M., Blader, P., Rosa, F., Peyrieras, N., and Vriz, S. 2006. Mechano-sensory organ regeneration in adults: The zebrafish lateral line as a model. Mol. Cell. Neurosci. 33: 180-187.

Ever, L. and Gaiano, N. 2005. Radial 'glial' progenitors: Neurogenesis and signaling. Curr. Opin. Neurobiol. 15: 29-33.

Fame, R.M., Brajon, C., and Ghysen, A. 2006. Second-order projection from the posterior lateral line in the early zebrafish brain. Neural Develop. 1: 4. doi: 10.1186/1749-8104-1-4.

Garcia-Bellido, A.C. and Garcia-Bellido, A. 1998. Cell proliferation in the attainment of constant sizes and shapes: The Entelechia model. Int. J. Dev. Biol. 42: 353-362.

Ghysen, A. and Dambly-Chaudière, C. 2004. Development of the zebrafish lateral line. Curr. Opin. Neurobiol. 14: 67-73.

Gilmour, D.T., Maischein, H.M., and Nusslein-Volhard, C.
2002. Migration and function of a glial subtype in the vertebrate peripheral nervous system. Neuron 34: 577-588.

Gilmour, D., Knaut, H., Maischein, H.M., and Nusslein-Volhard, C. 2004. Towing of sensory axons by their migrating target cells in vivo. Nat. Neurosci. 7: 491-492.

Gompel, N., Dambly-Chaudière, C., and Ghysen, A. 2000. Neuronal differences prefigure somatotopy in the zebrafish lateral line. Development 128: 387-393.

Gompel, N., Cubedo, N., Thisse, C., Thisse, B., DamblyChaudière, C., and Ghysen, A. 2001. Pattern formation in the lateral line of zebrafish. Mech. Dev. 105: 69-77.

Grant, K.A., Raible, D.W., and Piotrowski, T. 2005. Regulation of latent sensory hair cell precursors by glia in the zebrafish lateral line. Neuron 45: 69-80.

Haas, P. and Gilmour, D. 2006. Chemokine signaling mediates self-organizing tissue migration in the zebrafish lateral line. Dev. Cell 10: 673-680.

Haines, L., Neyt, C., Gautier, P., Keenan, D.G., Bryson-Richardson, R.J., Hollway, G.E., Cole, N.J., and Currie, P.D. 2004. Met and Hgf signaling controls hypaxial muscle and lateral line development in the zebrafish. Development 131: 48574869.

Harrison, R.G. 1904. Experimentelle Untersuchungen über die Entwicklung der Sinnesorgane der Seitenlinie bei den Amphibian. Arch. Mikrosk. Anat. 63: 35-149.

Hernandez, P.P., Olivari, F.A., Sarrazin, A.F., Sandoval, P.C., and Allende, M.L. 2007. Regeneration in zebrafish lateral line neuromasts: Expression of the neural progenitor cell marker sox 2 and proliferation-dependent and-independent mechanisms of hair cell renewal. Dev. Neurobiol. 67: 637654.

Hudspeth, A.J. 1989. How the ear's works work. Nature 341: 397-404.

Itoh, M. and Chitnis, A.B. 2001. Expression of proneural and neurogenic genes in the zebrafish lateral line primordium correlates with selection of hair cell fate in neuromasts. Mech. Dev. 102: 263-266.

Kawamura, G., Masuma, S., Tezuka, N., Koiso, M., Jinbo, T., and Namba, K. 2003. Morphogenesis of sense organs in the bluefin tuna Thunnus orientalis. In The big fish bang (eds. H.I. Browman and A.B. Skiftesvik), pp. 123-135. Institute of Marine Research, Bergen, Norway.

Kimmel, C.B., Ballard, W.W., Kimmeln, S.R., Ullmann, B., and Schilling, T.F. 1995. Stages of embryonic development of the zebrafish. Dev. Dyn. 203: 253-310.

Kollmar, R., Nakamura, S., Kappler, J., and Hudspeth, A.J. 2001. Expression and phylogeny of claudins in vertebrate primordia. Proc. Natl. Acad. Sci. 98: 10196-10201.

Laguerre, L., Soubiran, F., Ghysen, A., König, N., and DamblyChaudière, C. 2005. Cell proliferation in the developing lateral line system of zebrafish embryos. Dev. Dyn. 233: 466472.

Lecaudey, V. and Gilmour, D. 2006. Organizing moving groups during morphogenesis. Curr. Opin. Cell Biol. 18: 102-107.

Ledent, V. 2002. Postembryonic development of the posterior lateral line in zebrafish. Development 129: 597-604.

Li, Q., Shirabe, K., and Kuwada, J. 2004. Chemokine signaling regulates sensory cell migration in zebrafish. Dev. Biol. 269: 123-136.

Lopez-Schier, H. and Hudspeth, A.J. 2005. Supernumerary neuromasts in the posterior lateral line of zebrafish lacking peripheral glia. Proc. Natl. Acad. Sci. 102: 1496-1501.

Lopez-Schier, H. and Hudspeth, A.J. 2006. A two-step mechanism underlies the planar polarization of regenerating sensory hair cells. Proc. Nat1. Acad. Sci. 103: 18615-18620.

Lopez-Schier, H., Starr, C.J., Kappler, J.A., Kollmar, R., and Hud- 
speth, A.J. 2004. Directional cell migration establishes the axes of planar polarity in the posterior lateral-line organ of the zebrafish. Dev. Cell 7: 401-412.

Merkle, F.T., Tramontin, A.D., Garcia-Verdugo, J.M., and Alvarez-Buylla, A. 2004. Radial glia give rise to adult neural stem cells in the subventricular zone. Proc. Natl. Acad. Sci. 101: $17528-17532$.

Metcalfe, W.K. 1985. Sensory neuron growth cones comigrate with posterior lateral line primordium cells in zebrafish. $J$. Comp. Neurol. 238: 218-224.

Metcalfe, W.K., Kimmel, C.B., and Schabtach, E. 1985. Anatomy of the posterior lateral line system in young larvae of the zebrafish. I. Comp. Neurol. 233: 377-389.

Müller, A., Homey, B., Soto, H., Ge, N., Catron, D., Buchanan, M.E., McClanahan, T., Murphy, E., Yuan, W., Wagner, S.N., et al. 2001. Involvement of chemokine receptors in breast cancer metastasis. Nature 410: 50-56.

Northcutt, R.G. 1997. Evolution of gnathostomes lateral line ontogenies. Brain Behav. Evol. 50: 25-37.

Odenthal, J., Haffter, P., Vogelsang, E., Brand, M., van Eeden, F.J., Furutani-Seiki, M., Granato, M., Hammerschmidt, M., Heisenberg, C.P., Jiang, Y.J., et al. 1996. Mutations affecting the formation of the notochord in the zebrafish, Danio rerio. Development 123: 103-115.

Parinov, S., Kondrichin, I., Korzh, V., and Emelyanov, A. 2004. Tol2 transposon-mediated enhancer trap to identify developmentally regulated zebrafish genes in vivo. Dev. Dyn. 231: 449-459.

Pichon, F. and Ghysen, A. 2004. Evolution of posterior lateral line development in fish and amphibians. Evol. Dev. 3: 187193.

Santos, F., MacDonald, G., Rubel, E.W., and Raible, D.W. 2006. Lateral line hair cell maturation is a determinant of aminoglycoside susceptibility in zebrafish (Danio rerio). Hear. Res. 213: 25-33.

Sapède, D., Gompel, N., Dambly-Chaudière, C., and Ghysen, A. 2002. Cell migration in the postembryonic development of the fish lateral line. Development 129: 605-615.

Sarrazin, A., Villablanca, E., Nuñez, V., Sandoval, P., Ghysen, A., and Allende, M. 2006. Proneural gene requirement for hair cell differentiation in the zebrafish lateral line. Dev. Biol. 295: 534-545.

Schlosser, G. 2002a. Development and evolution of lateral line placodes in amphibians I. Development. Zoology (Jena) 105: 119-146.

Schlosser, G. 2002b. Development and evolution of lateral line placodes in amphibians. II. Evolutionary diversification. Zoology (Jena) 105: 177-193.

Schlosser, G. 2006. Induction and specification of cranial placodes. Dev. Biol. 294: 303-351.

Smith, S.C., Lannoo, M.J., and Armstrong, J.B. 1990. Development of the mechanoreceptive lateral-line system in the axolotl: Placode specification, guidance of migration, and the origin of neuromast polarity. Anat. Embryol. (Berl.) 182: $171-180$

Song, J., Yan, H.Y., and Popper, A.N. 1995. Damage and recovery of hair cells in fish canal (but not superficial) neuromasts after gentamicin exposure. Hear. Res. 91: 63-71.

Stone, L.S. 1937. Further experimental studies of the development of lateral-line sense organs in amphibians observed in living preparations. J. Comp. Neurol. 68: 83-115.

Tarby, M.L. and Webb, J.F. 2003. Development of the supraorbital and mandibular lateral line canals in the cichlid, Archocentrus nigrofasciatus. J. Morphol. 255: 44-57.

Thompson, D. 1917. On growth and form, Abridged edition. Cambridge University Press, Cambridge.
Valentin, G., Haas, P., and Gilmour, D. 2007. The chemokine SDFla coordinates tissue migration through the spatially restricted activation of Cxcr7 and Cxcr4b. Curr. Biol. 17: 1026-1031.

Villablanca, E., Renucci, A., Sapède, D., Lec, V., Soubiran, F., Sandoval, P., Dambly-Chaudière, C., Ghysen, A., and Allende, M. 2006. Control of cell migration in the zebrafish lateral line: Implication of the gene "tumour-associated calcium signal transducer," tacstd. Dev. Dyn. 235: 1578-1588.

Webb, J.F. 1989. Gross morphology and evolution of the mechanoreceptive lateral-line system in teleost fishes. Brain Behav. Evol. 33: 205-222.

Webb, J.F. and Shirey, J.E. 2003. Post-embryonic development of the cranial lateral line canals and neuromasts in zebrafish. Dev. Dyn. 228: 370-385.

Whitfield, T.T. 2005. Lateral line: Precocious phenotypes and planar polarity. Curr. Biol. 15: R67-R70. doi: 10.1016/ j.cub.2004.12.059.

Williams, J.A. and Holder, N. 2000. Cell turnover in neuromasts of zebrafish larvae. Hear. Res. 143: 171-181.

Winklbauer, R. and Hausen, P. 1985. Development of the lateral-line system in Xenopus laevi. III: Developemnt of the suborbital system in triploid embryos and larvae. J. Embryol. Exp. Morphol. 88: 183-192.

Witten, P.E. 1997. Enzyme histochemical characteristics of osteoblasts and mononucleated osteoclasts in a teleost fish with acellular bone (Oreochromis niloticus, Cichlidae). Cell Tissue Res. 287: 591-599.

Yang, Y., Chen, J., Engel, J., Pandya, S., Chen, N., Tucker, C., Coombs, S., Jones, D.L., and Liu, C. 2006. Distant touch hydrodynamic imaging with an artificial lateral line. Proc. Natl. Acad. Sci. 103: 18891-18895.

Yasuoka, A., Hirose, Y., Yoda, H., Aihara, Y., Suwa, H., Niwa, K., Sasado, T., Morinaga, C., Deguchi, T., Henrich, T., et al. 2004. Mutations affecting the formation of posterior lateral line system in Medaka, Oryzias latipes. Mech. Dev. 121: 729-738. 


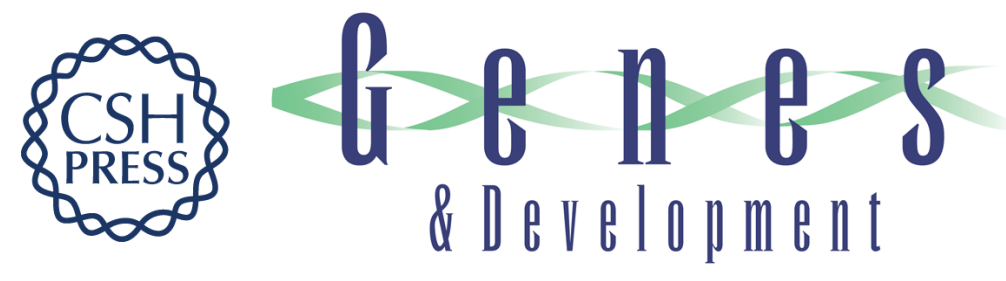

\section{The lateral line microcosmos}

Alain Ghysen and Christine Dambly-Chaudière

Genes Dev. 2007, 21:

Access the most recent version at doi:10.1101/gad.1568407

References This article cites 60 articles, 11 of which can be accessed free at: http://genesdev.cshlp.org/content/21/17/2118.full.html\#ref-list-1

License

Email Alerting Receive free email alerts when new articles cite this article - sign up in the box at the top Service right corner of the article or click here.

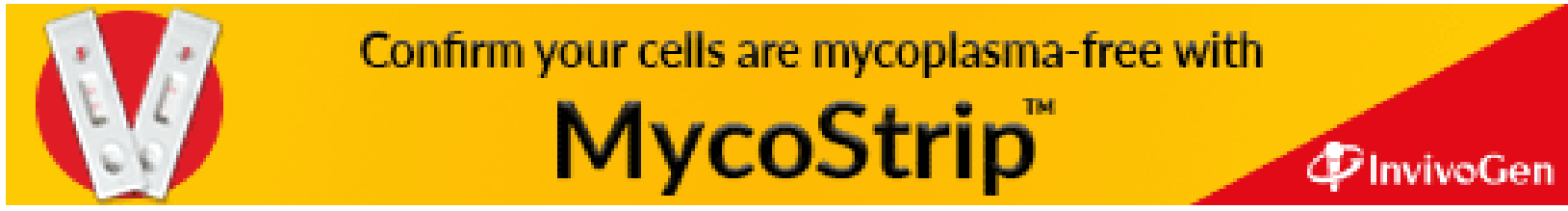

